J. Clin. Chem. Clin. Biochem.

Vol. 25, 1987, pp. 5-14

(C) 1987 Walter de Gruyter \& Co. Berlin $\cdot$ New York

\title{
Aminolaevulinate Dehydratase Porphyria in Infancy A Clinical and Biochemical Study
}

\author{
By S. Thunell \\ Department of Clinical Chemistry, S:t Göran Hospital, Stockholm, Sweden \\ L. Holmberg and J. Lundgren \\ Department of Pediatrics, University of Lund, Lund, Sweden
}

(Received January 28/July 31, 1986)

Summary: Homozygous deficiency of aminolaevulinate dehydratasè (porphobilinogen synthase, EC 4.2.1.24) was diagnosed in a small child. The clinical presentation was unique since severe symptoms were already present in the neonatal period. The patient, a boy, now three-years old, had recurrent attacks of pain, vomiting, hyponatraemia and symptoms of polyneuropathy engaging motor functions including respiration. The clinical course of the disease from birth on is related, as are the results of various attempts at therapy. The patient excreted large amounts of 5-aminolaevulinic acid and coproporphyrin and minor amounts of porphobilinogen in the urine. Faecal excretion of coproporphyrin and harderoporphyrin was increased as was erythrocyte porphyrin concentration. Diagnosis was established by the finding that erythrocyte aminolaevulinate dehydratase activity was less than 5 per cent of normal in the patient and between 26 and 51 per cent of normal in both the parents, the grandfathers and a sibling. The activity of the enzyme could not be restored by the addition of dithiothreitol $\left(10^{-3} \mathrm{~mol} / \mathrm{l}\right)$ alone, or in combination with zinc or manganese in varying concentrations. The enzyme $K_{\mathrm{m}}$ did not differ between affected and nonaffected members of the family.

\section{Introduction}

Haem, the prosthetic group of a series of important protein catalysts, is synthesized from succinate and glycine in eight sequential enzymatic steps, the first being the formation of 5 -aminolaevulinic acid by $\delta$ aminolaevulinate synthase. If the activity of one of the enzymes in the chain is decreased, due to inherited or acquired deficiency, the rate of flow in the affected part of the metabolic pathway is reduced and the substrate of the defective enzyme may accumulate. In the inheritable disorders of acute intermittent porphyria, variegate porphyria and hereditary coproporphyria, the impairment of catalytic power and diminished rate of haem synthesis give rise to a derepression of the initial enzyme of the sequence, subsequent overload of the physiologically weak third step of the pathway, and overproduction of the porphyrin precursors 5-aminolaevulinic acid and porphobilinogen. In acute exacerbations the diseases are recognized by increased urinary excretion of the porphyrin precursors and by severe attacks of abdominal pain, and neurological and psychiatric disturbances. The symptoms are often precipitated by exposure to drugs, organic solvents and other agents capable of accelerating the rate of haem synthesis. For these reasons the conditions in question are generally referred to as acute or inducible forms of porphyria.

Recently, two cases of a fourth type of acute porphyria have been described (1), characterized by decreased activity of aminolaevulinate dehydratase, the 
second enzyme in the metabolic chain. The patients' symptoms appeared after puberty and were typical of acute hepatic porphyria. In contrast to other hepatic porphyrias the gene defect was clinically manifest only in what seemed to be a homozygous state. In the present communication the clinical and biochemical findings are described in a patient with aminolaevulinate dehydratase porphyria, presenting with severe symptoms at birth.

Aminolaevulinate dehydratase (porphobilinogen synthase, EC 4.2.1.24) is the second enzyme in the haem synthetic pathway, catalysing the condensation of two molecules 5-aminolaevulinic acid to form the heterocyclic monopyrrol, porphobilinogen (fig. 1).
The enzyme protein is octameric, composed of apparently identical subunits of a molecular weight of about 35000 Daltons. It is inhibited by some heavy metals, e. g. lead, (2) which explains the elevated urine levels of 5-aminolaevulinic acid in lead poisoning (3). One subunit of the enzyme contains one zinc atom and eight sulfhydryl groups. It is assisumed that the lead ions replace zinc in the molecule, resulting in loss of enzymatic activity by formation of lead mercaptide (4). Sulfhydryl reagents such as glutathione, cysteine and dithiothreitol as well as zinc and manganese ions (5) restore the activity of the enzyme in vitro $(2,6,7)$. The enzyme is inhibited by succinylacetone, a compound which accumulates in hereditary tyrosinaemia (8).

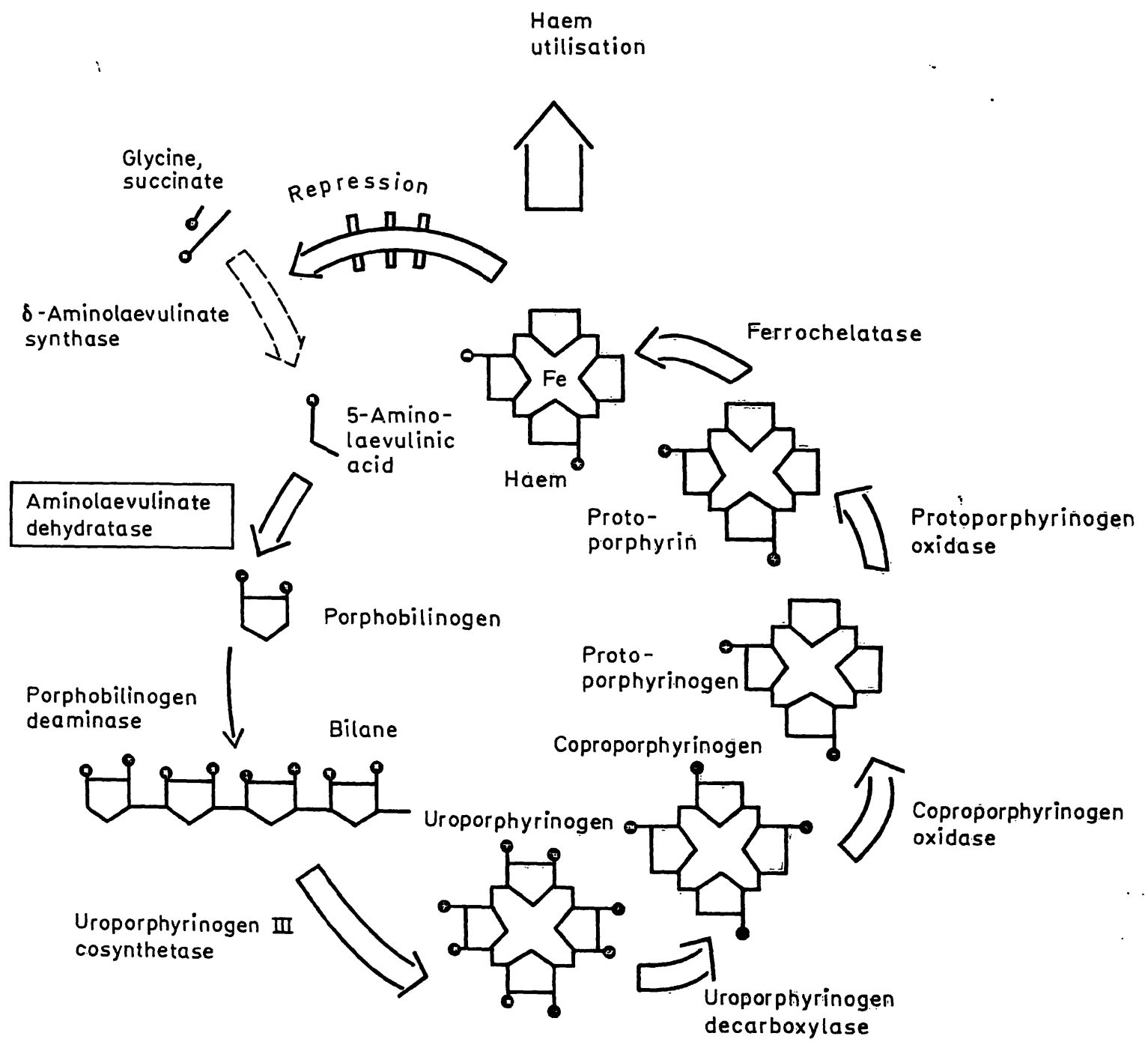

Fig. 1. Haem synthesis and regulation (36). Haem is synthesized from succinate and glycine by eight catalytic steps. It forms an active centre in enzymes that metabolize steroid hormones and drugs, handle toxic oxygen radicals and synthesize nicotinic acid. Increased utilisation of haem and the subsequent decrease of the haem pool will derepress the initial step of the metabolic chain, catalysed by $\delta$-aminolaevulinate synthase, and accelerate haem synthesis. In instances of impaired enzyme function, the intensified traffic through the pathway may cause overload of the deficient step and accumulation in the cell of the substrate for the enzyme in question. The dashed arrow indicates the enzymatic step fluctuating in activity with the size of regulatory free heme pool. $\uparrow$ indicates carboxylic porphyrin side chain. 


\section{Case History}

The propositus was a boy born on April 27, 1983 as the fourth child of a 36-year-old woman, who had given birth to 3 normal children in 1975, 1979 and 1981. She also had 4 spontaneous abortions in gestational weeks 7 to 13 . Ultrasound examination just prior to two of the abortions showed growth-retarded foetuses, and microscopical examinations of the abortuses showed regressive changes in the decidua. The three healthy children were all born at term after normal pregnancies. The pregnancy with the patient was also uneventful. A routine ultrasound examination in the 32nd week showed a slightly reduced biparietal diameter. During the pregnancy the mother took no medications except iron, aspirin on a few occasions and Scheriproct suppositories for haemorrhoids. Labor started spontaneous movements of all limbs. No grasp reflex or Moro under epidural analgesia with bupivacain $0.25 \%$ (total dose 18 ml) combined with blockage of the pudendal nerves also with bupivacain (total dose $20 \mathrm{ml}$ ). Slight depression of foetal heart rate was noted.

Immediately after birth the patient had shallow respiration and showed muscular hypotonia but had a normal heart rate. Even after ventilation with oxygen for three minutes the hypotonia persisted. Apgar scores at 1, 5 and 10 minutes were 4, 7 and 7. Birthweight was $3990 \mathrm{~g}$, length $48.5 \mathrm{~cm}$ and head circumference $33.5 \mathrm{~cm}$.

The patient was brought to the intensive care unit for observation. On examination he had a general hypotonus but showed spontaneous movements of all limbs. No grasp reflex or Moro reflex could be elicited. Muscle tendon reflexes were weak or absent. The liver was slightly enlarged. On grounds of progressive respiratory insufficiency and cyanosis he was connected to a ventilator at the age of $\mathbf{2 0}$ hours. Treatment with antibiotics (gentamicin, benzylpenicillin), phenobarbital, dexamethasone and furosemide was started. The initial investigations, including EEG, ultrasound of the head and abdomen, liver function tests, serum creatinine, plasma and urine aminograms, urinary excretion of organic acids, mucopolysaccharides and oligosaccharides, thyroid function tests and blood ammonia were all within normal limits. Blood haemoglobin was $160 \mathrm{~g} / \mathrm{l}$ on the 1 st day and $121 \mathrm{~g} / \mathrm{l}$ on the 3 rd day. The reticulocyte count was $10.5 \%$ on the 3 rd day and $6.4 \%$ on the 4 th day. A blood transfusion was given. Lumbar puncture on the first day showed a spinal protein concentration of $1.25 \mathrm{~g} / 1$ and a normal cell count. At $31 / 2$ weeks of age spinal protein was $0.60 \mathrm{~g} / 1$. EMG at 9 and 12 days revealed an absence of motor responses in all muscles recorded, and fibrillation potentials. Sensory neurography showed involvement also of the sensory nerves.

The ventilator treatment had to be continued for several weeks. During the first weeks muscular hypotonia was profound and no limb movements were observed. After 3 weeks spontaneous muscular activity of the limbs slowly returned. EMG at 29 days of age still showed signs of denervation but the motor unit potentials in proximal muscle groups had improved. At 5 weeks of age the child could finally be extubated and managed without ventilatory support. He gradually started to eat and muscular tonus successively improved. At 8 weeks of age there were normal Moro and abdominal wall reflexes but head control was poor and tendon reflexes absent. The clinical improvement continued and the patient was discharged at the age of 61 days without a firm diagnosis. The blood haemoglobin concentration was $115 \mathrm{~g} / \mathrm{l}$. Further blood transfusions were not needed. At follow-up he first showed a good development of motor skills and muscle strength. At one year of age, although still hypotonic, he could sit steadily, roll around, move things from one hand to the other and use a fairly good pincette grasp. He understood some instructions and spoke a few words. At 15 months he started to crawl and at 18 months he walked unsupported. His muscular tonus was then almost normal and the muscle tendon reflexes within normal limits. EMG at 10 months was practically normal. The motor unit potentials showed some changes consistent with an old neurogenic damage. Conduction velocities in both motor and sensory nerves were within normal limits. Although the patient's weight gain had been acceptable the family complained of feeding problems. The boy had frequent respiratory infections with otitis media. During such episodes he refused to eat and vomited for long periods. He seemed to dislike all different formulae tested.

At the age of 23 months (in March 1985) the patient became more irritable, cried at intervals and refused to eat and drink. A progressive muscular weakness of both legs appeared. The patient could no longer walk or even stand up on his legs which seemed to hurt on touching. A slight tremor in the arms was apparent when he attempted purposeful movements. On examination the tendon reflexes in both legs had disappeared. $\mathrm{X}$-rays of the lumbar and sacral region revealed a slight cleft in the 5th lumbar vertebra but myelography was normal. The agents used for anaesthesia at the myelography were pentobarbital, phentanyl, pancuron, atropine, neostigmine and nitrous oxide. Spinal protein was $0.14 \mathrm{~g} / \mathrm{l}$. EMG showed a slight reduction of motor unit potentials. At this time a porphyrin metabolic investigation was done (See below: "Design of the study").

The patient's condition first improved without treatment but at the beginning of May 1985 general muscular pain and anorexia reappeared. Intravenous treatment with $10 \%$ glucose in water (glucose: $5 \mathrm{~g} / \mathrm{d} \cdot \mathrm{kg}$ body weight) was started. Since no clinical improvement occurred, carbohydrate was added in the form of Caloreen, $250 \mathrm{~g}$ daily through a naso-gastric tube. Still his condition deteriorated with involvement of respiratory function. The breathing pattern became inverted and lung $X$ ray showed almost complete absence of diaphragmatic movements consistent with bilateral phrenic nerve palsy. The patient ceased moving legs and arms, probably due partly to motor involvement, partly to the intensive pain evidently elicited by the movements. A central venous catheter was inserted and haematin (Panhematin, Abbott), $2 \mathrm{mg}$ per $\mathrm{kg} \mathrm{BW}$ was given twice daily for 6 days. No immediate effect of haematin was seen. Other treatments included total parenteral nutrition with a high glucose content, metoprolol to control the blood pressure which fluctuated, but now and then rose to $140 / 100 \mathrm{~mm} \mathrm{Hg}$, and continuous positive airway pressure (CPAP) to counteract atelectasis. The blood haemoglobin concentration was normal (121 $\mathrm{g} / \mathrm{l})$ but erythrocyte concentrate $(5-8 \mathrm{ml} / \mathrm{kg})$ was given nevertheless on five occasions (from May 23 to June 9) in an attempt to suppress the erythropoiesis and hence 5-aminolaevulinate synthase activity in the bone marrow and possibly also to replace the missing enzyme (9). An episode of Klebsiella septicaemia was successfully treated with cloxacillin and netilmicin. EMG on June 7th showed no motor responses at all on stimulation, either in the legs or in the arms. Abundant fibrillation potentials were seen. Sensory neurography was normal. No further impairment of respiratory function occurred. Slowly, over a period of weeks, he regained some muscle strength and a normal respiratory pattern. A general muscular atrophy especially of the legs persisted as well as bilateral contractures of both ankle joints. Oral feeding was reinstituted, and the patient was discharged on July $2 n d$.

In August 1985 the patient once again had an upper respiratory tract infection. Another transfusion of erythrocyte concentrate was given, but his condition became worse. As before, he stopped eating and drinking, appeared restless, seemed to have sore legs, arms and body, developed tremor in both arms and had a general sick appearance. A central venous catheter was inserted and total parenteral nutrition again started with a high carbohydrate content. A partial blood exchange, $80 \mathrm{ml}$ per $\mathrm{kg}$ BW was performed and the condition seemed to stabilize but did not improve. An acute episode of inappropriate vasopressin secretion intervened accompanied by weight gain, and there was a fall of serum sodium to $110 \mathrm{mmol} / \mathrm{l}$ with simultaneous high urine osmolarity ( $530 \mathrm{mosmol} / \mathrm{l})$, but this responded to fluid restriction. In September 1985 another blood exchange 
was performed followed by a course of Panhermatin ( $2 \mathrm{mg}$ per $\mathrm{kg} \mathrm{BW}$ twice daily) for 6 days. No clear effect was seen. In October 1985 a trial with a novel haem arginate compound (Normosang) $3 \mathrm{mg} / \mathrm{kg} \mathrm{BW}$ for 4 days was made. This also failed to bring about a clinical improvement. Since then the patient's condition has varied with periods of deterioration alternating with improvement. At present (April 1986) his clinical status is characterized by plantar flexion contractures of the ankle joints and severe calf muscle atrophy. He can sit but not stand. The hand movements are impaired. Muscle pain on movements of the extremitites seems to vary from day to day. Speech development is delayed, but otherwise the patient does not appear retarded. Because of anorexia and vomiting he continues to be totally dependent on a specially composed parenteral formula for his nutrition. Skin symptoms suggestive of cutaneous porphyria have not developed. Blood haemoglobin has been $105-114 \mathrm{~g} / \mathrm{l}$ after the neonatal period, which is in the normal range. The reticulocyte count has varied from $0.3 \%$ to $4.4 \%$, usually around $2 \%$, indicating hyperhaemolysis, which accords with a picture of a markedly increased normoblastic erythropoiesis in the bone marrow smear. The patient is not transfusion-dependent and has no splenomegaly. Serum iron was $8 \mu \mathrm{mol} / 1$, and total iron binding capacity was 52 $\mu \mathrm{mol} / \mathrm{l}$ in May 1985 prior to blood therapy.

\section{Family History}

The families on the mother's and father's side have been traced back for several generations. There is no known consanguinity (fig. 2). A neurological disorder similar to the patient's has not been found in any other member.

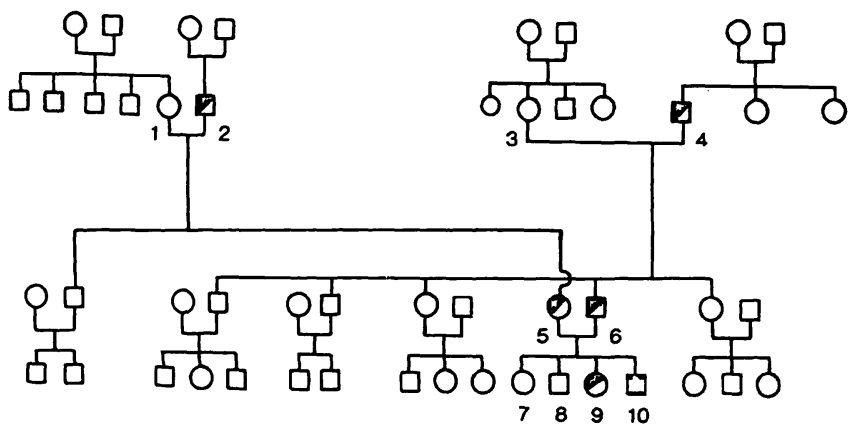

Fig. 2. Pedigree of the relatives. For explanation of the numerical symbols see table 1 .

\section{Experimental}

Design of study

The index case, his brother, two sisters, parents and paternal and maternal grandparents were investigated with regard to urinary excretion of porphyrin precursors and porphyrins, concentration of porphyrins in faeces, erythrocyte porphyrin and the erythrocyte enzymes, porphobilinogen deaminase and aminolaevulinate dehydratase. In the case of the propositus, urine and faeces contained increased concentrations of porphyrins, which were separated, identified and quantitated. The effect on aminolaevulinate dehydratase activity of the addition of dithiothreitol, zinc and manganese was investigated in haemolysates from the propositus (no detectable original enzyme activity), from three relatives showing $26-50$ per cent normal enzyme activity, and from two relatives showing normal enzyme activity. Erythrocyte aminolaevulinate dehydratase kinetics were studied in haemolysates from the parents, both showing only 35 per cent of normal enzyme activity, and in haemolysate from the maternal grandmother who exhibited a normal enzyme activity. The urine of the propositus was tested for aminolaevulinate dehydratase inhibitors, and the blood and urine were analysed for lead.
The establishment of age-related reference values for erythrocyte aminolaevulinate dehydratase activity

In order to establish reference values for erythrocyte aminolaevulinate dehydratase, the results from an investigation of 880 persons between 2 and 88 years were plotted against age, and the line of regression determined (fig. 3). The individuals selected for the study had been referred to the laboratory for investigation, but found to carry no significant clinical or biochemical evidence of a porphyrin metabolic disturbance. It was considered that any undetected latent cases of acute intermittent porphyria, who might be hidden in the material, would not significantly bias the distribution of values. Separate studies of cases of acute intermittent porphyria, where the carrier state could be established, have shown that in this condition the distribution of erythrocyte aminolaevulinate dehydratase activity does not deviate from normal.

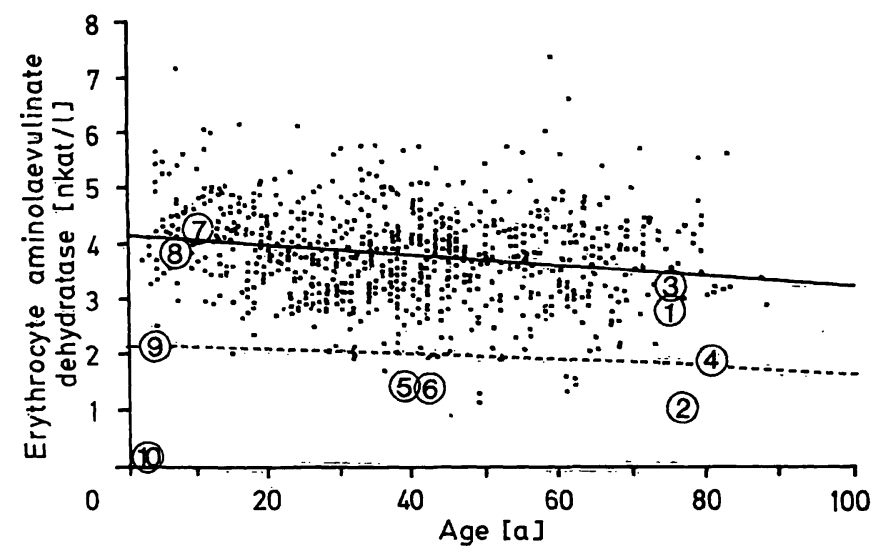

Fig. 3. Relation between age and erythrocyte aminolaevulinate dehydratase activity in normal individuals. Enzyme activities of the patient (10) and his relatives (1)- (9). For explanations of the numerical symbols see table 1 . Lower range for 50 per cent activity of the normal agematched average mean is indicated by the broken line.

\section{Materials}

Porphyrins used for standards were obtained from Porphyrin Products, Utah, USA. Ion exchange columns for purification of porphobilinogen, 5-aminolaevulinic acid and porphyrins prior to analysis were purchased from Bio-Rad Laboratories, Richmond, California, USA. Silica gel thin layer chromatography plates used for separation of faecal porphyrins were Concentration Zone Merck HPTLC-Fertigplatten Sicone Gel 60 with fluorescence indicator F 254, supplied by Kebo Grave, Stockholm, Sweden.

\section{Methods}

For the determination of erythrocyte porphobilinogen deaminase (uroporphyrinogen I synthase, EC 4.3.1.8) activity, the packed red blood cell procedure of Magnussen et al. (10) was used. The activity of erythrocyte aminolaevulinate dehydratase activity was determined by the Europeen Standardized Method (11), before and after activation with dithiothreitol $10^{-3} \mathrm{~mol} / \mathrm{l}$ (12). The effect on the activity of the enzyme of addition of manganese and zinc in varying concentrations was studied as described by Chiba \& Kikuchi (13). Inhibitor activity of urine, directed against aminolaevulinate dehydratase, was investigated by addition of undiluted urine or urine diluted $1: 5$ and $1: 10$ with saline $(0.2 \mathrm{ml})$ to an haemolysate $(1 \mathrm{ml})$ from a person with normal erythrocyte enzyme activity. Enzyme activity was determined as described above. Kinetic parameters of aminolaevulinate dehydratase were determined by enzyme assay (11) using varying concentrations of 5-aminolaevulinic acid as substrate $(0.1-10 \mu \mathrm{mol} / \mathrm{l})$. 
5-Aminolaevulinic acid and porphobilinogen were quantitated in urine by the method of Mauzerall \& Granick (14) after separation by anion-cation exchange chromatography as described by Doss \& Schmidt (16). The individual porphyrins in urine were separated and quantitated without prior derivatization, by high performance liquid chromatography (17) and by use of an octadecylsilane precolumn (18). Porphyrins in faeces were separated as methyl esters (19) by thin layer chromatography (20) and individually quantitated after elution from the chromatographic plate with a chloroform-ethanol mixture (21). Three-carboxylated porphyrin was identified by the position in the chromatogram between coproporphyrin and protoporphyrin. Total faecal porphyrin was determined as the sum of the individual fractions. Erythrocyte porphyrin was assayed according to Piomelli (22).

\section{Results}

\section{Biochemical}

As evident from table 1, the propositus excreted large amounts of 5-aminolaevulinic acid and coproporphyrin in the urine, while the concentration of porphobilinogen was only slightly elevated. Faeces were investigated twice. On one occasion the concentration of porphyrin was normal, on the other moderately increased amounts were found, with significantly increased coproporphyrin, suburoporphyrin and porphyrin migrating in thin layer chromatography as a 3-carboxylated variety, the latter dominating the analytical picture. The concentration of erythrocyte porphyrin was considerably increased.
The activity of aminolaevulinate dehydratase was not restored by the addition of dithiothreitol $\left(10^{-3} \mathrm{~mol} / \mathrm{l}\right)$ or by zinc or manganese $\left(10^{-1}-10^{-7} \mathrm{~mol} / \mathrm{l}\right)$ alone or in combination.

The activity of erythrocyte porphobilinogen deaminase of the propositus was found to be higher than can be inferred from the values of the grandparents, parents and siblings. The urine of the proband did not contain any substance capable of inhibiting the enzyme in an haemolysate from a normal person. One of the sisters, both parents and the two grandfathers exhibited erythrocyte aminolaevulinate dehydratase activities less than 52 per cent of the average normal for the age group (tab. 1). Although this is not unique, very few of the 880 presumably normal individuals investigated had enzyme values in this range of the distribution (fig. 3). The parents of the proband, with erythrocyte enzyme activities of 35 per cent of normal, were investigated with regard to kinetic characteristics of the enzyme. The activities followed Michaelis-Menten kinetics (fig. 4) and gave $K_{\mathrm{m}}$ values similar to that determined for the enzyme of a normal relative. As 'expected, differing maximal velocities were recorded for the enzyme, being 55-60 per cent of normal. In the case of the relatives with low aminolaevulinate dehydratase activities (the two parents, one sister, the maternal grandfather), additions of dithiothreitol, zinc and manganese ions in the assay
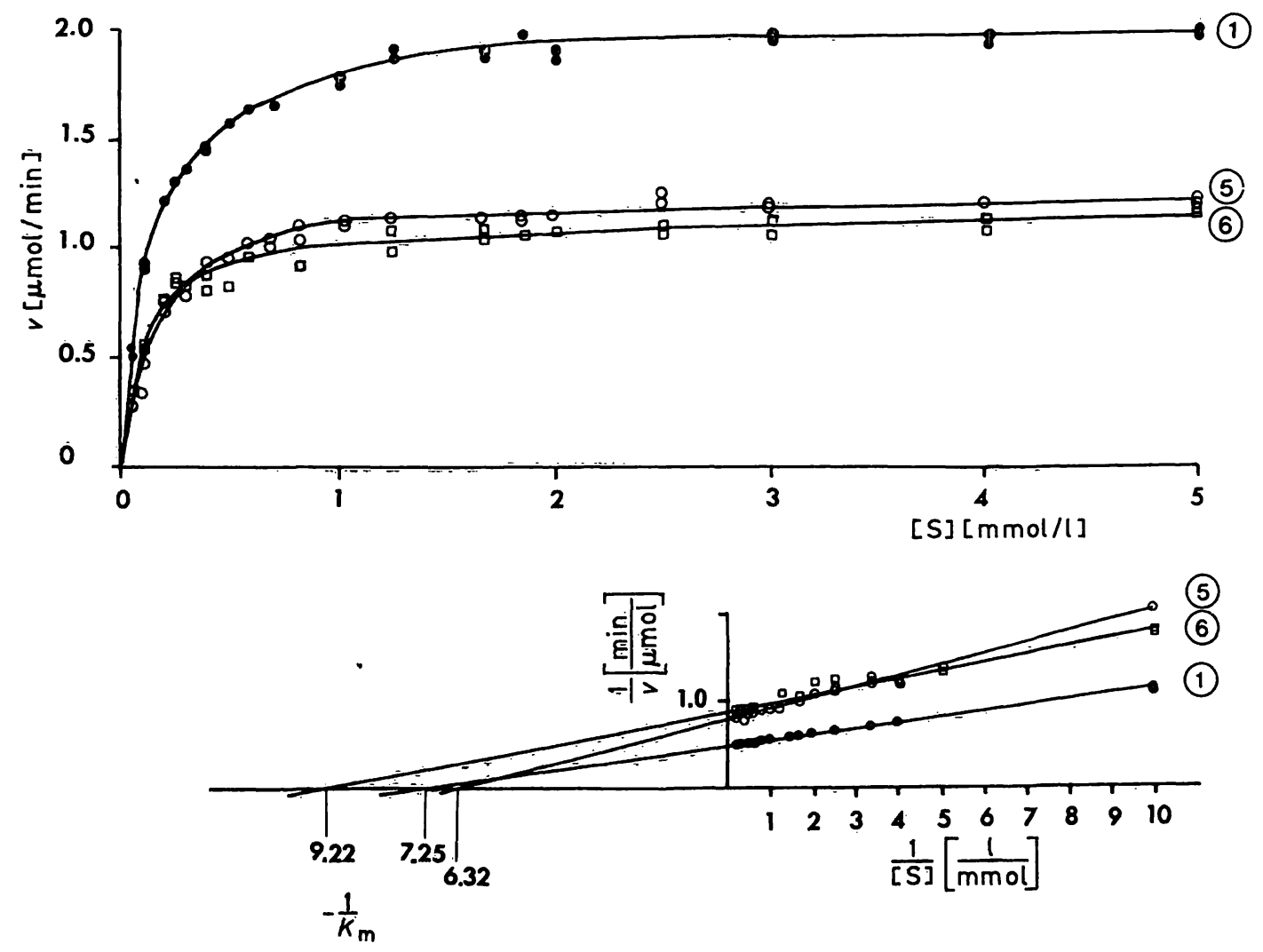

Fig. 4. Effect on activity of aminolaevulinate dehydratase of varying the concentration of 5-aminolaevulinic acid, in haemolysates from two individuals with decreased erythrocyte enzyme activity (() and (6) and from one person with normal activity of the enzyme (1)). For explanation of the numerical symbols see table 1. 


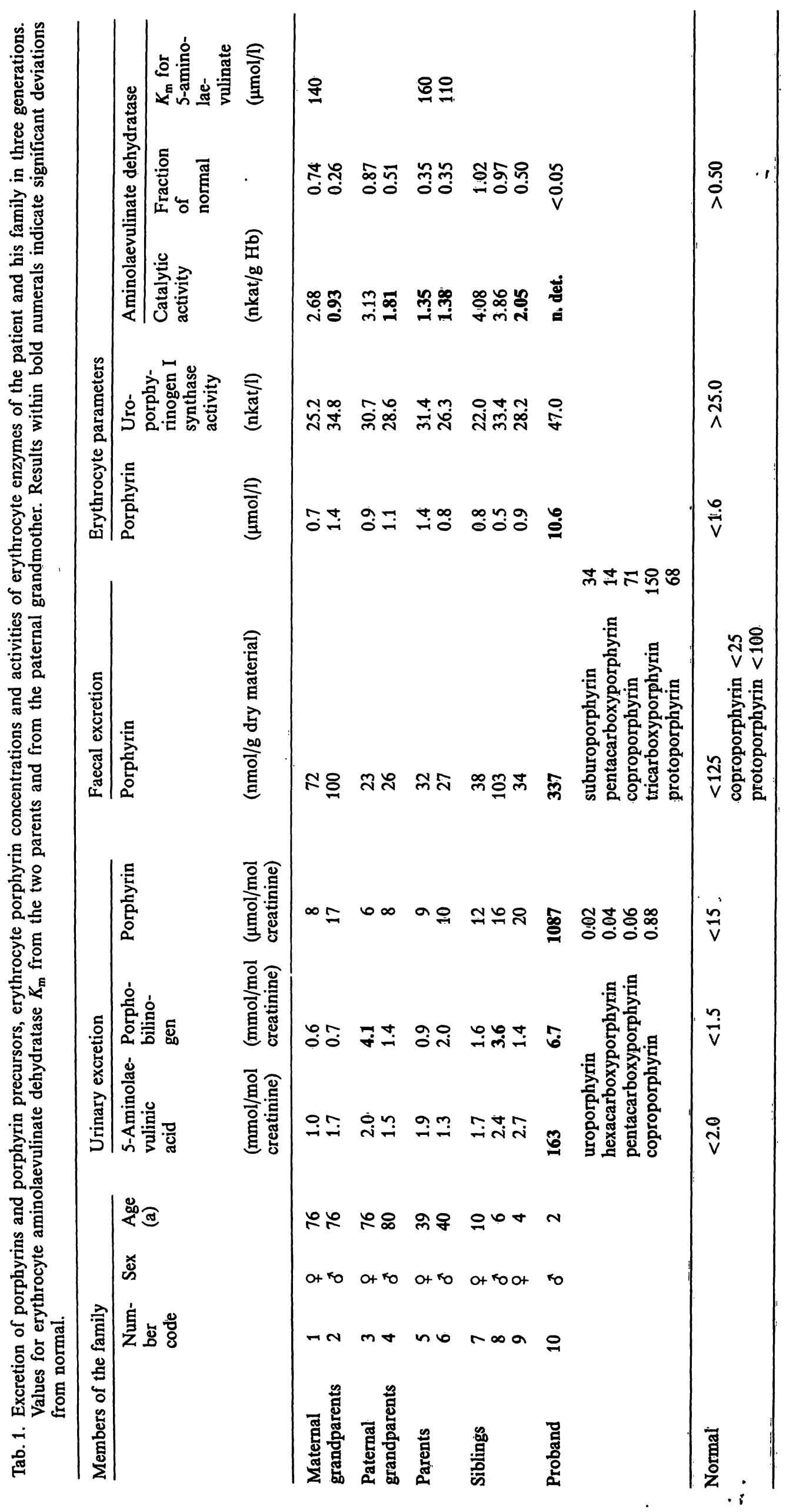


gave rise to slight increases of the recorded enzyme activities, of the same magnitude as in persons with normal enzyme activities (fig. 5). Also the patterns of enzyme inhibition at higher zinc and manganese concentrations, and the partial reversal of this inhibition by dithiothreitol, are the same for enzyme deficient persons and normals.

Two of the individuals with normal erythrocyte aminolaevulinate dehydratase activities, i.e. the paternal grandmother and the brother of the propositus, exhibit slightly elevated porphobilinogen concentrations in the urine (tab. 1). The oldest sister, who has the highest erythrocyte aminolaevulinate dehydratase activity of all the relatives, has a lower borderline activity of red cell porphobilinogen deaminase. With the exception of the propositus, and the younger of the two sisters who shows a slight increase in the concentration of porphyrin in the urine, none of the individuals with decreased activities of aminolaevulinate dehydratase shows evidence of any metabolic disturbances in the haem synthetic chain.

\section{Results of treatment}

The main metabolic abnormalities in the patient, e.g. the massive urinary excretion of 5 -aminolaevulinic acid and coproporphyrin, were present during the whole clinical course described above. Parenteral ad- ministration of glucose $(5 \mathrm{~g} / \mathrm{d} \cdot \mathrm{kg}$ body weight), did not alter this excretion, nor were the neurological symptoms alleviated. Two courses of haematin treatment were given. One of these is shown in figure 6. The excretion decreased somewhat during the first days of treatment but then increased again during the course. Coproporphyrin excretion was even increased. In the second course of haematin, given some months later, no response at all in the excretion of 5aminolaevulinic acid was seen (not shown). Figure 7 shows the metabolic response to haem-arginate. The excretion of 5-aminolaevulinic acid and coproporphyrin did not decrease but rather showed a tendency to increase, and the symptoms were not influenced. In addition, the patient has, with some benefit, been treated with physiotherapy and splints to counteract muscular atrophy and contractures.

\section{Discussion}

At first, the diagnosis of porphyria was not considered. The post-natal asphyxia, respiratory failure and muscular paralysis combined with the electromyographic findings of total axonal degeneration were consistent with diagnoses such as progressive spinal muscular atrophy, congenital Guillain-Barré syndrome or toxic neuropathy. Manifestations of the acute hereditary forms of porphyria are rare in child-
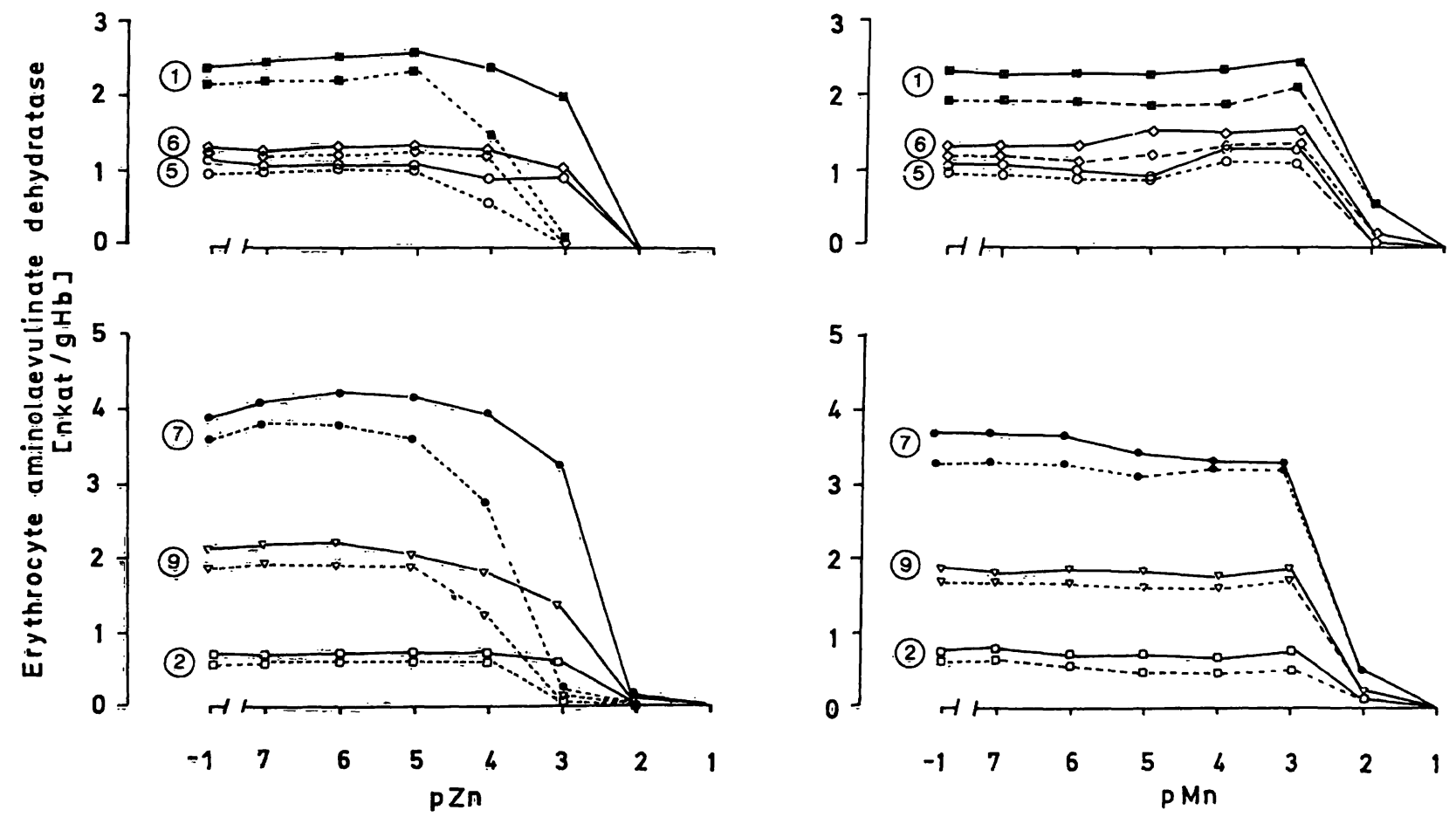

Fig. 5. Effects on activity of aminolaevulinate dehydratase of varying the concentrations of zinc and manganese ions, respectively, alone and in combination with dithiothreitol $\left(10^{-3} \mathrm{~mol} / \mathrm{l}\right)$. Solid lines connect observations from assays with dithiothreitol added. The symbols (1) and (7) indicate haemolysates from persons with normal erythrocyte aminolaevulinate dehydratase activity; (2), (5), (6), and (9) haemolysates from individuals with decreased enzyme activity (tab. 1). $\mathrm{pZn}, \mathrm{pMn}=-\log 10$ of $\mathrm{Zn}^{2+}, \mathrm{Mn}^{2+}$ concentration. 


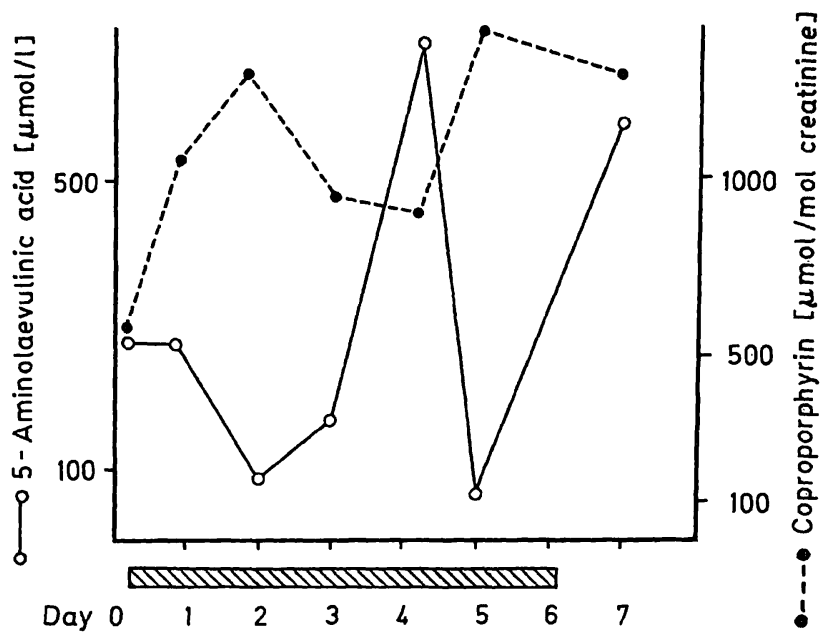

Fig. 6. Urinary excretion of 5-aminolaevulinic acid and coproporphyrin during a 6-day-course of Panhematin treatment $(2 \mathrm{mg} / \mathrm{kg}$ BW twice daily) in aminolaevulinate dehydratase porphyria.

hood. Clinical attacks of acute intermittent porphyria in children have been described but are exceptional (23). The symptoms and signs of variegate porphyria start after puberty. The same is generally the case for hereditary coproporphyria. Also in the two cases of aminolaevulinate dehydratase porphyria hitherto described the symptoms first appeared in adolescence. In no instance has acute hereditary porphyria been diagnosed in a symptomatic neonate.

The clinical course of the proband, characterized by remissions and exacerbations of irritability, anorexia and polyneuropathy, however, prompted us to investigate the porphyrin metabolism. The findings of a heavy excretion of 5-aminolaevulinic acid and of coproporphyrin, but only a slight increase of urinary porphobilinogen, increased erythrocyte porphyrin concentration and depressed activity of erythrocyte aminolaevulinate dehydratase suggested lead intoxication (tab. 1). On the other hand, no exposure to heavy metals could be shown, and urinary and whole blood levels of lead were normal. Further, the activity of the enzyme could neither be restored by a thiol reagent such as dithiothreitol, nor by zinc or manganese ions, so an explanation other than heavy metal intoxication had to be found. The possibility of inhibition of the enzyme by succinylacetone, which is produced in hereditary tyrosinaemia, was considered, but metabolic screening excluded that disease and the urine did not contain any substance capable of inhibiting aminolaevulinate dehydratase activity, as in tyrosinaemia (8). Since the prevalence of acute intermittent porphyria in Sweden is high, the activity of erythrocyte porphobilinogen deaminase was investigated in the proband as well as in the rest of the

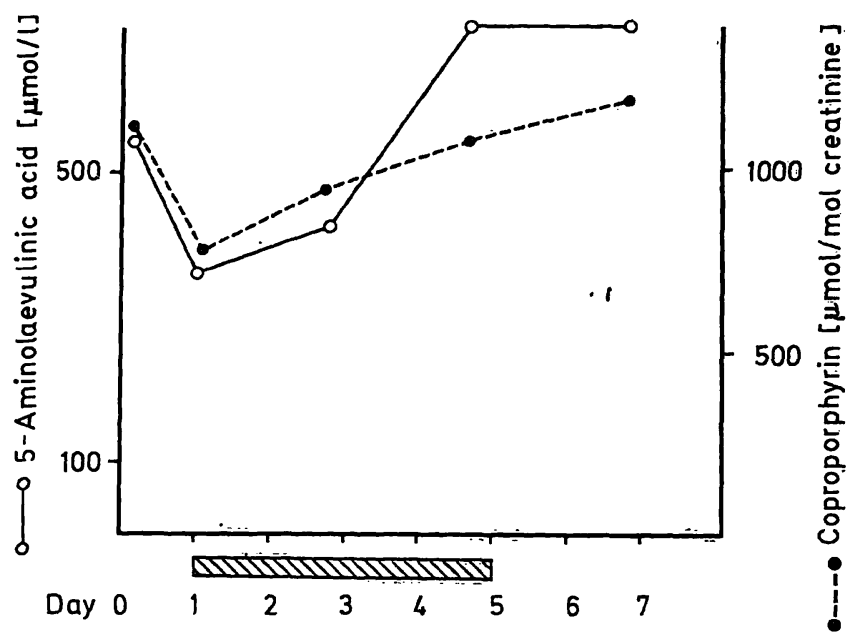

Fig. 7. Urinary excretion of 5-aminolaevulinic acid and coproporphyrin during a 4-day-course of haem-arginate treatment ( $3 \mathrm{mg} / \mathrm{kg} \mathrm{BW}$ daily) in aminolaevulinate dehydratase porphyria.

blood relatives. As evident from table 1 the activity of this enzyme in the proband was found to be in the upper borderline region, which might be a reflection of the presence in the blood of immature red cell elements. With the exception of one of his sisters (No. 7, tab. 1), who exhibited a lower borderline level, all the relatives had normal values. No evidence for the occurrence of acute intermittent porphyria in the kindred could thus be obtained. Further, the excretion patterns of porphyrins and porphyrin precursors in the proband and the findings of elevated erythrocyte porphyrin were not consistent with this condition.

Investigation of the family, on the other hand, revealed that several of the members through three generations had erythrocyte aminolaevulinate dehydratase activities below 50 per cent of normal. In humans the activity of aminolaevulinate dehydratase is under genetic influence (23), the enzyme probably being under the control of an autosomal gene with two different alleles $(24,25)$ located on chromosome 9 (26). The activity of the enzyme shows wide variation in a reference population, which is evident in figure 3, and activities below 50 per cent of the average normal are encountered also in a few presumably normal individuals. Nevertheless, the available evidence indicates that the disposition of the aminolaevulinate dehydratase gene differs from normal in the kindred in question. In 1979 Bird et al. (28) reported a family with inherited deficiency of aminolaevulinate dehydratase, encountered during a population study. The enzyme deficiency occurred through three generations in an autosomal dominant pattern. The enzyme activities recorded in the red cells of the affected individuals ranged between 22 and 41 per 
cent of normal. In no instance did clinical or biochemical symptoms accompany the deficiency. In the same year Doss et al. described two patients with acute porphyria whose symptoms first appeared in adolescence and were associated with a severe decrease in aminolaevulinate dehydratase activity. Further investigations of the patients and their families have provided evidence of a structural mutation of the gene encoding the enzyme, with production of a noncatalytic protein. Clinical manifestations occurred in the two apparently homozygous patients but not in their presumably heterozygous relatives (1, $29,30,31$ ). Our index patient differs from those described by Doss et al. by exhibiting severe symptoms from birth, but nevertheless the symptoms were typical of acute porphyria. The biochemical profile resembles that in Doss' patients, i. e., massive excretion of 5-aminolaevulinic acid, modest increase of the porphobilinogen concentration in urine, heavy coproporphyrinuria, elevated erythrocyte porphyrin concentration and very low aminolaevulinate dehydratase activity in the red blood cells. On one occasion analyses of faecal excretion of porphyrins were normal. During a clinical exacerbation, however, the concentration of porphyrin in faeces increased, yielding a thin layer chromatography pattern reminiscent of that seen in harderoporphyria (32). The observations thus strongly suggest that the proband is homozygous for a defective aminolaevulinate dehydratasecontrolling gene.

A study of the pedigree gives support to this assumption (fig. 2). One of the sisters, the two parents and both the grandfathers, all healthy, have erythrocyte enzyme activities ranging between 26 and 51 per cent of the average normal for their respective age groups. These findings indicate that they are asymptomatic heterozygous carriers. The study of aminolaevulinate dehydratase kinetic parameters of the parents did not disclose any deviations from normal with regard to substrate affinity of the enzyme (tab. 1). The values obtained for $K_{\mathrm{m}}$ are slightly lower than those reported for normal individuals in other communications $(28$, $31,33)$, discrepancies which might be due to differences in environmental lead pressure between the populations in questions $(31,34)$. Nor were any significant differences found when zinc, manganese and dithiothreitol activation of the enzyme was compared between the heterozygotes and the nonaffected individuals in the kindred. Taken together, the observations imply that the index case belongs to a family with aminolaevulinate dehydratase deficiency, inherited through three generations in an autosomal dominant mode. The condition appears to depend on a mutation leading either to abolished enzyme synthesis or to the synthesis of an inactive enzyme. In the heterozygous state it seems to be without obvious pathological significance for the individual, but in homozygous form it gives rise to severe porphyric symptoms. As in the previously studied family with aminolaevulinate dehydratase porphyria (29), the disorder in the present family follows the general scheme of an autosomal recessive disease (37).

Apart from the different age of onset, the present case differs in some other important aspects compared with the two patients described by Doss et al. In addition to the neurological symptoms, the patient also has signs of a mild haemolytic state with increased reticulocyte counts and marked bone marrow erythropoietic activity. Thus our patient seems not to have a pure hepatic form of porphyria, since there is also evidence for an erythropoietic component. The response to treatment also differs from the experience of Doss et al. In contrast to them we saw no beneficial effects of concentrated glucose infusion. The findings might indicate an even more severe enzyme deficiency in our case.

In acute intermittent porphyria haematin or haemarginate treatment is often effective in inducing a clinical remission accompanied by a decrease in the excretion of 5-aminolaevulinic acid and porphobilinogen. Haem infusions are believed to increase the free haem pool of the liver cells and thereby cause a feed-back inhibition of aminolaevulinate synthase. We noticed no consistent effect of haem in our case of aminolaevulinate dehydratase porphyria. No explanation for this can be offered at the moment, but perhaps haem oxygenase was induced by the administered haem. This would lead to accelerated haem degradation and a diminished free regulatory haem pool.

The question of how haem synthesis is maintained under circumstances of a practically total block of one of the steps in the pathway presents an intriguing problem in the present case as well as in other forms of homozygous porphyria. A common denominator for these conditions seems to be overload of the erythroid ferrochelatase step, as evidenced by accumulation of protoporphyrin in the red blood cells. This is the case in congenital erythropoietic porphyria (36), in hepatoerythropoietic porphyria $(37,38)$, variegate porphyria (39), and harderoporphyria (32) as well as in the previously reported cases of aminolaevulinate dehydratase porphyria (1). In the present case, a metabolic overflow also seems to occur at the coproporphyrinogen oxidase step, as indicated by the increased excretion of coproporphyrin and 3carboxylated porphyrin. The metabolic significance of these observations remains to be elucidated. 
As can be noted in figure 3 , activities of aminolaevulinate dehydratase below 50 per cent of normal are not exceptional in the population, being found in 16 out of the 880 persons investigated. If these individuals are heterozygous carriers of aminolaevulinate dehydratase deficiency, the prevalence of this condition is about 2 per cent. The implications are of obvious practical importance since a gene frequency of this magnitude will lead to a significant number of marriages between heterozygotes and generation of individuals homozygous in the condition. The fact that the mother of the patient reported in the present communication had four spontaneous abortions may

\section{References}

1. Doss, M., Tiepermann, R., Schneider, J. \& Schmid, H. (1979) Klin. Wochenschr. 57, 1123-1127.

2. Nakao, K., Wada, O. \& Yano, Y. (1968) Clin. Chim. Acta $19,319-325$.

3. Haeger-Aronsen, B., Abdulla, M. \& Fristedt, B. J. (1971) Arch. Environ. Health 23, 440-445.

4. Tsukamoto, I., Yoshinaga, T. \& Sano, S. (1979) Biochim. Biophys. Acta $570,167-178$.

5. Chiba, M. \& Kikuchi, M. (1984) Tox. Appl. Pharm. 73, 388-394.

6. Lichtman, H. C. \& Feldman, F. (1963) J. Clin. Invest. 42, $830-839$.

7. Sassa, S., Granick, S. \& Kappas, A. (1975) Ann. NY Acad. Sci. $244,419-439$.

8. Lindblad, B., Lindstedt, S. \& Steen, G. (1977) Proc. Natl. Acad. Sci. USA 74, $4641-4645$.

9. Battle, A. M. dc., Bustos, N. L., Stella, A. M., Wider, E. A., Conti, H. A. \& Mendez, A. (1983) Int. J. Biochem. 15, $1261-1265$.

10. Magnussen, C. R., Levine, J. B., Doherty, J. M., Cheesman, J. O. \& Tschudy, D. P. (1974) Blood 44, 857-868.

11. Berlin, A. \& Schaller, K. H. (1974) Z. Klin. Chem. Klin. Biochem. 12, 389-390.

12. Granick, J. L., Sassa, S., Granick, S., Levere, R. D. \& Kappas, A. (1973) Biochem. Med. 8, 149-159.

13. Chiba, M. \& Kikuchi, M. (1984) Tox. Appl. Pharm. 73, 388-394.

14. Mauzerall, D. \& Granick, S. (1956) J. Biol. Chem. 219, 435-446.

15. Davis, R. D. \& Andelman, S. L. (1976) Arch. Environ. Health 15, 53-59.

16. Doss, M. \& Schmidt, A. (1971) Z. Klin. Chem. Klin. Biochem. 9, 415-418.

17. Ford, R. E., Ou, C. N. \& Ellefsson, R. D. (1981) Clin. Chem. 27, 397-400.

18. Englert, E., Wayne, A. W., Wales, E. E. \& Straight R. C. (1979) J. High Resol. Chromatogr. Chromatogr. Commun. 2, 570-574.

19. Wilson, J.-H. P., Van den Berg, J.-W. O., Edixhoven-Bostidjk, A. \& Van Gastel-Qvist, L. H. M. (1978) Clin. Chim. Acta 89, 165-171. indicate that the homozygous deficiency of aminolaevulinate dehydratase usually is not compatible with life, and that the few cases of the disorder observed represent rare exceptions from this rule. Probably it would be useful to routinely investigate paternal and maternal erythrocyte aminolaevulinate dehydratase activities in cases of habitual abortions. Work is in progress to evaluate this proposal.

\section{Acknowledgement}

We thank Miss Ann Henriksson, Mrs Lena Ernstgård and Miss Christina Ström for skilfull technical assistance.
20. With, T. K. (1975) Dan. Med. Bull. 22, 74-80.

21. Herlin, G. \& Thunell, S. In preparation.

22. Piomelli, S. (1973) J. Lab. Clin. Med. 81, 932-940.

23. Barclay N. (1974) Arch. Dis. Child. 49, 404-406.

24. Sassa, S., Granick, S., Bickers, D. R., Levere, R. D. \& Kappas, A. (1973) Enzyme 16, 326-333.

25. Battistuzzi, G., Petrucci, R., Silvagni, L., Urbani, F. R. \& Caiola, S. (1981) Ann. Hum. Genet. 45, $223-229$.

26. Benkmann, H. G., Bogdanski, P. \& Goedde, H. W. (1983) Hum. Hered. 33, $62-64$.

27. Eiberg, H., Morh, J. \& Nielsen, L. (1983) Clin. Genet. 23, $150-154$.

28. Bird, T. D., Hamernyik, P., Nutter, J. Y. \& Labbe, R. F. (1979) Am. Hum. Genet. 31, 662-668.

29. Brandt, A. \& Doss, M. (1981) Hum. Genet. 58, 194-197.

30. de Verneuil, H., Doss, M., Brusco, N., Beamount, C. \& Nordmann, Y. (1985) Hum. Genet. 69, 174-177.

31. Doss, M., Schneider, J., Tieperman, R. \& Brandt, A. (1982) Clin. Biochem. 15, 52-55.

32. Nordmann, Y., Grandchamp, B., de Verneuil, H. \& Phung, L., Cartigny, B., Fontaine, G. J. (1983) J. Clin. Invest. 00, 1139-1149.

33. Kondo, M., Urata, G. \& Shimizu, Y. (1983) Clin. Sci. 65, $423-428$.

34. Anderson, P. M. \& Desnick, R. J. (1979) J. Biol. Chem. $254,6924-6930$.

35. Vogel, F. \& Motulski, A. G. (1979) In: Human Genetics, pp. 194-264, Springer, Berlin - Heidelberg - New York.

36. Meyer, U. \& Schmid, R. (1978) In: The Metabolic Basis of Inherited Disease, p. 1166, McGraw-Hill Book Co., New York.

37. Czarnecki, D. B. (1980) Arch. Dermatol. 116, 307-311.

38. Elder, G. H., Smith, S. G., Herrero, C., Mascaro, J. M., Lecha, M., Muniesa, A. M., Czarnecki, D. B., Brenan, J., Poulos, U. \& Salamanca, R. E. (1981) Lancet I, 916-919.

39. Mustajoki, P. (1985) Personal communication.

40. Doss, M., Tiepermann, R. \& Köpp, W. (1984) Lancet $I$, 292.

Associate professor Dr Stig Thunell

Department of Clinical Chemistry

S:t Göran Hospital, Box 12500

S-11281 Stockholm 